Van-Tho Hoang and Young-Jin Yum*

\title{
Optimization of the fabrication conditions and effects of multi-walled carbon nanotubes on the tensile properties of various glass fibers/unsaturated polyester resin composites
}

https://doi.org/10.1515/epoly-2018-0033

Received February 19, 2018; accepted April 29, 2018; previously published online July 9,2018

\begin{abstract}
Conventional glass fiber/unsaturated polyester resin (UPR) composites were fabricated by four layers to verify the optimum fabrication conditions such as the initial curing temperature, fiber changes and vacuum. Before that another optimum condition for stir mixing multi-walled carbon nanotubes (MWCNTs) into UPR was further investigated based on the initial curing temperature. Exothermic temperature measurements, density measurements, thermo-gravimetric analysis and tensile testing were utilized to identify the effects of these factors on the UPR and composite laminates. Consequently, an initial curing temperature range of $25^{\circ} \mathrm{C}-35^{\circ} \mathrm{C}$ was recommended to start the polymerization. In addition, the fiber combination and applying vacuum were also represented as the other optimum conditions in composite fabrication. The optimum initial curing temperature was applied for modifying UPR with $0.1 \mathrm{wt} . \%$ MWCNTs. Then, all of optimum conditions were used to fabricate glass fibers/ modified UPR composites. The higher tensile strength and modulus of fiber combination with the adding of MWCNTs were obtained at $25.29 \mathrm{MPa}$ and $1.39 \mathrm{GPa}$, respectively. The results indicate that simple MWCNT mixing can be used in industry due to the reduction of the fabrication time and better tensile properties.
\end{abstract}

Keywords: composite; glass fiber; multi-walled carbon nanotubes; tensile properties; unsaturated polyester resin.

\section{Introduction}

Polymer composites have been utilized as alternative materials for many decades to avoid exhausting natural

*Corresponding author: Young-Jin Yum, School of Mechanical Engineering, University of Ulsan, Daehak-ro 93, Nam-gu, Ulsan 680749, South Korea, Tel.: +82 522592132, e-mail: yjyum@ulsan.ac.kr Van-Tho Hoang: School of Mechanical Engineering, University of Ulsan, Daehak-ro 93, Nam-gu, Ulsan 680-749, South Korea resources. Among them, glass fiber reinforced thermosetting resin is a common material due to its use in electronics, furnishings, aerospace, boats and marine, medical and automobile applications $(1,2)$. This material can result in desirable characteristics including low density, high specific strength, high specific modulus, high corrosion resistance and low cost (3). In particular, glass fiber/ polyester composite materials have represented excellent behavior to reinforce the specifically expected direction of structures compared to conventional metals.

The enhancement of material characteristics has attracted a wide range of research to improve fuel efficiency, reduce carbon dioxide emissions in the equipment industry (4) and increase the displacement of ships, particularly to satisfy the strength criteria for transport systems. Composite fabrication methods for thermosetting polymer composites have been improved to partially meet the above trends. Hand lay-up is a manual technique, while vacuum-assisted resin transfer molding has been considered the most efficient fabrication method based on its higher volume fraction, low void contents, low weight, low operating cost, low production rates, its being less harmful and its ability to accommodate complex shapes (5).

In fact, the mechanical properties of composite materials are strongly dependent on the strengths and moduli of the matrix and fiber as well as the bonding strength between the matrix and fiber (6). Therefore, modifying the fiber or matrix has increased by simply adding high potential candidates. Multi-walled carbon nanotubes (MWCNTs) have been widely applied due to their slightly lower properties but much lower cost compared to single-walled carbon nanotubes in the series of carbon nanotubes since 1991 when Iijima (7) first discovered the unique structure of carbon nanotubes. Several researches have focused on dispersing MWCNTs into thermosetting resins including epoxy (8-11), phenolic (12) and unsaturated polyester (13). Some issues were encountered and compared to determine the best choice for dispersion quality between MWCNTs and the thermosetting polymer $(14,15)$. In addition, based on the strong development of nano-technology, reinforcement components were also treated by growing MWCNTs on their surfaces (16-22). Some methods have been proposed to add MWCNTs on the surface of fibers such as chemical vapor deposition 
(CVD), physical vapor deposition (PVD) (18) and a simple chemical method (19), where CVD is the most widely used (16-18, 20-22). Actually, MWCNTs impart different positive effects in each fabrication method. Thus, the mechanical properties of novel composite materials based on MWCNT-coated fibers/neat resins (23-32), MWCNTdispersed resin/neat fibers (33-41) or a combination of both treated fibers and a treated matrix $(42,43)$ have been considered to determine the optimum modification methods. According to the load transfer mechanism (44) and stress transfer theory (45), axial stress and the interfacial shear strength (IFSS) of composite structures can be improved with an appropriate content of added MWCNTs. The basic mechanical behavior was mainly concentrated on the IFSS of a single fiber and matrix by fragmentation, tensile and micro-droplet (pull-out) tests in most studies. Some significant influences of the MWCNTs on the material properties were observed such as a $69 \%$ higher tensile strength (29), 94\% higher IFSS (30), $80 \%$ higher fracture toughness $\left(\mathrm{G}_{\mathrm{IC}}\right)$ and about $32 \%$ smaller coefficient of thermal expansion (34). Warrier et al. (42) and Godara et al. (43) showed that the best performance was achieved from fiber treatment and polymer treatment was slightly less effective than fiber treatment, while the combination resulted in the lowest effect based on the $\mathrm{G}_{\mathrm{IC}}$, thermal expansion coefficient, crack propagation and IFSS results.

On the other hand, Dai et al. (28) presented some drawbacks, difficulties and challenges regarding both the MWCNT-modified matrix and fibers. For example, it is not easy to obtain a high quality dispersion in mixing MWCNTs in the matrix due to the highly attractive Van der Waals force of MWCNT particles. A high aspect ratio strongly reduces the viscosity of the polymer such that a small amount of added MWCNTs cannot fully salvage the performance of the additive. In case of fiber edition, a high quality of coating cannot be achieved easily because of the impurity from the metal catalysts and various generations of carbon inside the high temperature chamber. In addition, due to the limitation of size, CVD and PVD are difficult to apply to mass production and they can only be used to locally grow nanoparticles on the surface of fibers. Moreover, pure carbon nanotube fibers were recommended to overcome the problems encountered by processing CNTs and these fibers showed extremely high mechanical, thermal and electrical properties, whereas creating a laminate is still challenging $(46,47)$. Furthermore, MWCNTs were also used to solve the out-of-plane weakness problem of conventional laminate composites to show their high potential and challenges $(48,49)$.
As can be seen from the literature review, so many researchers have been focusing on developing the mechanical properties of thermosetting composite materials. Mostly, the studies considered epoxy resin and carbon fiber. Several researches evaluated unsaturated polyester resin (UPR) $(6,13,15)$ and glass fibers $(6,28,32$, $33,35,36,41-43)$, especially not any topic related to the combination of chopped strand mat (CSM) and woven reinforced MWCNTs modified UPR, although UPR, CSM and woven are also well-known members in the composite world. In addition, dispersion methods of modified UPR and grown fibers by MWCNTs have been applied well only on a laboratory scale. Thus, further investigation of applying MWCNTs in mass production environments is very important. From our previous study (50), the increase of tensile properties of modified UPR was obtained by a simple dispersion method via the optimum parameters such as mixing temperature, hardener ratio and content of MWCNTs. Motivated by the above discussion, this study aims to obtain higher mechanical properties of conventional fibers/modified polymer composites based on some other optimum conditions in composite fabrication as well as in mixing MWCNTs into UPR. Therefore, reasonable initial curing temperatures of UPR were determined firstly according to exothermic temperatures, polymerization time, density and thermo-gravimetric analysis (TGA). Secondly, fibers were changed to find their behavior by thermal resistance and tensile properties. The effect of a vacuum was also checked by density, TGA and tensile properties of composite structures. Finally, all of optimum factors were applied to assess the influence of adding $0.1 \mathrm{wt} . \%$ of MWCNTs on tensile properties of various glass fibers/ edited UPR composites.

\section{Experiment}

\subsection{Materials}

Reinforcement components including glass fiber woven and glass fiber CSM were made by Kimchon Plant Company (Seoul, South Korea).

UPR (EC-304) and methyl ethyl ketone peroxide (MEKP) were made by Aekyung Chemical Company (Chung nam, South Korea).

The MWCNTs (CM-130) with an outside diameter of 10-15 nm, an inside diameter of 5-10 $\mathrm{nm}$, and length of 10-30 $\mu \mathrm{m}$ were supplied by Hanwha Chemical Company (Ulsan, South Korea). 


\subsection{Fabrication}

\subsubsection{Matrix modification}

According to our previous results (50), a higher tensile strength and higher dispersion quality can be obtained when mixing MWCNTs and UPR at a high temperature. In this study, MWCNTs were mixed with UPR by a Hot and Stir machine (HY-HS11, DS Global, Gyeonggi, South Korea) at $60^{\circ} \mathrm{C}$ and $2000 \mathrm{rpm}$ for $1 \mathrm{~h}$. Then, the mixing temperature was reduced to optimum initial curing temperature range. This step is very important because the curing time will be very short at a high temperature (Section 3.1), which may obstruct the fabrication procedure.

\subsubsection{Composite structure fabrication}

Generally, the composite laminate was fabricated with four layers of the fiber and matrix using a roller in a hand lay-up fabrication method. The ratio of fiber and matrix was kept as a constant (Table 1) to survey the effect of fiber changes, vacuum and adding MWCNTs. Here, the CSM weight fraction was $0.25(25 \%)$ and the woven weight fraction was $0.5(0.5 \%)$. Meanwhile, the neat or modified UPR was quickly mixed at an optimum hardener ratio (1 wt.\%) for $30 \mathrm{~s}$ by hand. After fabrication, the curing process was started at a certain temperature (from 25 to $35^{\circ} \mathrm{C}$ ) for $24 \mathrm{~h}$. Then, an oven (Hanyang Scientific equipment, Seoul, South Korea) was used for the post-curing process at $80^{\circ} \mathrm{C}$ for $2 \mathrm{~h}$ to remove air voids and improve cross-linking of the matrix and fiber. Finally, five tensile specimens in rectangular shape were cut by a diamond cutter (The University of Ulsan, Ulsan, South Korea) for each plate (the length was $200 \mathrm{~mm}$, the width was $20 \mathrm{~mm}$, the thickness was varied in each plate) without a tab.

In the case of applying a vacuum, a bleeder (Jet Korea Aerospace Industry, Gyeoungsangnam, South Korea), peel ply (Airtech, CA, USA) and a vacuum bag (Airtech,

Table 1: Fiber weight fraction in different cases.

\begin{tabular}{|c|c|c|c|c|c|}
\hline \multirow[t]{2}{*}{ No. } & \multirow[t]{2}{*}{ Components } & \multicolumn{4}{|c|}{ Weight fraction (\%) } \\
\hline & & CSM & Woven & MWCNTs & UPR \\
\hline 1 & MWCNTs+UPR & & & 0.1 & 100 \\
\hline 2 & CSM+UPR & 25 & & & 75 \\
\hline 3 & Woven+UPR & & 50 & & 50 \\
\hline 4 & CSM+Woven+UPR & 12.5 & 25 & & 62.5 \\
\hline 5 & CSM+MWCNTs+UPR & 25 & & 0.075 & 75 \\
\hline 6 & Woven+MWCNTs+UPR & & 50 & 0.05 & 50 \\
\hline 7 & CSM+Woven+MWCNTs+UPR & 12.5 & 25 & 0.0625 & 62.5 \\
\hline
\end{tabular}

CA, USA) were used for packing samples and mold after laminating. The high vacuum pump (W2V10, Woosung Automa, Gyeonggi, South Korea) was connected by a hose to assist fabrication process for $5 \mathrm{~h}$ to ensure UPR cured fully.

\subsection{Measurements}

\subsubsection{Curing temperature measurement}

A thermometer (FLUKE 568, Fluke corporation, WA, USA) was set at the center of the mixture to monitor the exothermic temperature of the chemical reaction between UPR and MEKP. In this study, the initial temperature was investigated based on the exothermic temperature and curing time. Twenty grams of UPR was poured into a jar and then, the jar was moved to a refrigerator in this case, $10.9^{\circ} \mathrm{C}$ and an oven at other different temperatures (28.5, 35.2 and $45.5^{\circ} \mathrm{C}$ ) for a few minutes to ensure a uniform temperature of the UPR. Next, 1 wt.\% of MEKP was added into the jar and mixed for $30 \mathrm{~s}$. Finally, a thermometer connected to a computer was used for data recording.

\subsubsection{Density measurement}

The densities of the pure UPR obtained at different initial curing temperatures and the composite samples were measured using an AND (GF-200, Precision Weighting Balances, MA, USA) apparatus at atmospheric pressure and $22^{\circ} \mathrm{C}$.

\subsubsection{Thermal gravimetric analysis (TGA)}

The thermal characteristics were evaluated using a TGA Q50 (V20.13, TA instruments, DE, USA) in a nitrogen environment ( $40 \mathrm{ml} / \mathrm{min}$ balance purge flow). The temperature was maintained under isothermal conditions for $5 \mathrm{~min}$ before it was increased to $800^{\circ} \mathrm{C}$ at a rate of $10^{\circ} \mathrm{C} / \mathrm{min}$. Roughly $10 \mathrm{mg}$ samples were prepared to evaluate the effects of the initial curing temperature, fiber and vacuum.

\subsubsection{Tension test}

The tension test was conducted using a universal testing machine (DTU-900MHN, Daekyung Tech and Testers, Incheon, South Korea) at a test speed of $2 \mathrm{~mm} / \mathrm{min}$ according to ASTM D 3099. An extensometer with a $50 \mathrm{~mm}$ gauge length was used. The tensile properties were analyzed to evaluate the effects of the making conditions, fiber 
changes, fabrication method and MWCNTs on the composite structures.

\section{Results and discussion}

\subsection{Effect of the initial curing temperature}

\subsubsection{Curing behavior of unsaturated polyester resin}

Resin modification was chosen as a simple method to improve the mechanical properties of the composite structure. In fact, the forming procedure of the composite structure can be naturally described by curing of the main binder (polyester). As a result, the geometry of the structure can be generated completely at the finishing time of curing. Actually, the curing behavior of UPR can be strongly accelerated by many factors such as the hardener content, temperature and other conditions (3). There are several reports detailing curing process results (51-53), where $1 \mathrm{wt.} \%$ of hardener was demonstrated as the optimum value for UPR due to the higher compressive strength and lower exothermic temperature (50).

Figure 1 shows the curing behaviors of UPR for different initial temperatures. Generally, the viscosity of UPR increased during the chemical reaction between the polyester and the hardener while the temperature increased simultaneously. Gelation formation occurred until the mixture was converted fully to the solid stage. It is clear that the total curing time at higher initial curing temperatures is shorter than at lower temperatures. The maximum exothermic temperature generated was $165.5^{\circ} \mathrm{C}$ at an initial temperature of $45.5^{\circ} \mathrm{C}$ with the shortest time (594 s) to reach the maximum temperature. On the other hand, the lowest initial curing temperature $\left(10.9^{\circ} \mathrm{C}\right)$ had the smallest

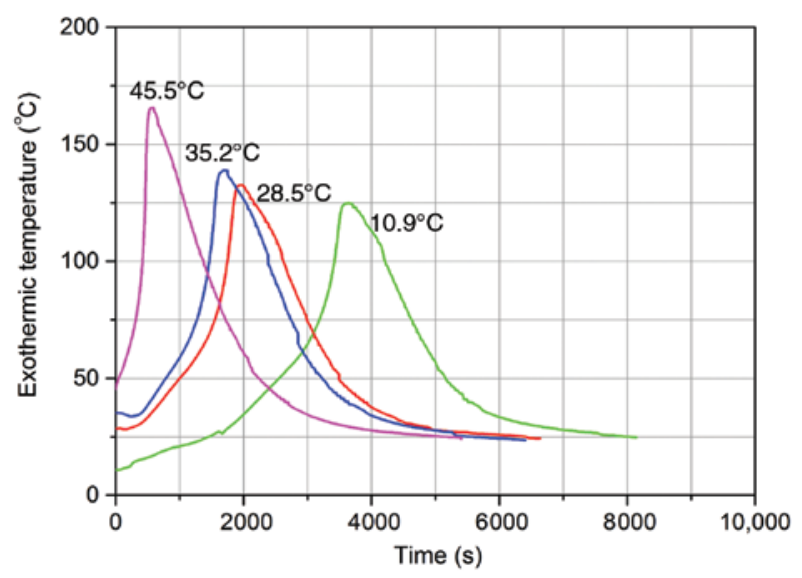

Figure 1: Curing behavior for different initial temperatures. exothermic temperature $\left(124.8^{\circ} \mathrm{C}\right)$ and took the longest time (3561 s) to reach the maximum temperature. With initial temperatures of $28.5^{\circ} \mathrm{C}$ and $35.2^{\circ} \mathrm{C}$, the exothermic temperatures were $132.6^{\circ} \mathrm{C}$ and $138.9^{\circ} \mathrm{C}$ and the times to reach these peaks were $1980 \mathrm{~s}$ and $1687 \mathrm{~s}$, respectively. The differences of the exothermic temperatures and curing times were not significantly different for initial temperatures in the range of $28.5^{\circ} \mathrm{C}-35.2^{\circ} \mathrm{C}$. In comparison with other results we can see that, lower temperature $\left(30^{\circ} \mathrm{C}\right)$ indicated a lower rate of reaction (51), but higher tensile properties were received (53). Based on this, the reason for cooling down the mixture from the high temperature before pouring the hardener into UPR in Section 2.2.1 can be explained. Indeed, the exothermic temperature was slightly reduced in both cases of initial temperatures of $28.5^{\circ} \mathrm{C}$ and $35.2^{\circ} \mathrm{C}$ because the chemical reaction was not immediately held after mixing the hardener. Therefore, the mixture was automatically cooled down because the heat was transferred to the room temperature. However, in the case of an initial curing temperature of $10.9^{\circ} \mathrm{C}$ (lower than room temperature), the exothermic temperature nonlinearly increased at the beginning. After curing, the temperatures in all cases were reduced similarly to room temperature $\left(25^{\circ} \mathrm{C}\right)$ after different times. This means that the cooling rate also changed depending on the initial curing temperature.

In another study, Zhang et al. (54) found the maximum exothermic temperature and the time to reach the peak temperature of another thermosetting resin (epoxy) were approximately $175^{\circ} \mathrm{C}$ and $150 \mathrm{~min}$, respectively. In comparison with the current result, epoxy has a much lower curing rate that means the solidification procedure is much longer than UPR. It can result in some limitations of fabrication methods using a vacuum for UPR such as vacuum bagging and resin infusion methods because the resin flow cannot transfer after the gelation time. Consequently, a vacuum should be applied as soon as possible to ensure UPR completely filled into fibers. It is also very important to consider thoroughly the curing time in mass production using UPR and a vacuum.

\subsubsection{Density of unsaturated polyester resin}

UPR is a thermosetting resin. Thus, theoretically, the volume of the sample should shrink after curing (55). This was confirmed in the value of the density of UPR obtained in this study. The samples from curing behavior investigation were reused to figure out density and TGA. In the liquid stage, the density of UPR is $1.15\left(\mathrm{~g} / \mathrm{cm}^{3}\right)$ (Table 2) and it is changed to $1.22\left(\mathrm{~g} / \mathrm{cm}^{3}\right)$ in the solid stage (Table 3 ). The same mass of UPR was obtained in 
Table 2: Characteristics of the materials.

\begin{tabular}{lll}
\hline Number & Material name & Density \\
\hline 1 & Woven & $570\left(\mathrm{~g} / \mathrm{m}^{2}\right)$ \\
2 & Chopped strand mat (CSM) & $300\left(\mathrm{~g} / \mathrm{m}^{2}\right)$ \\
3 & Unsaturated polyester resin (UPR) & $1.15\left(\mathrm{~g} / \mathrm{cm}^{3}\right)$ \\
4 & Multi-walled carbon nanotubes & Bulk: $0.04\left(\mathrm{~g} / \mathrm{cm}^{3}\right)$ \\
& (MWCNTs) & \\
\hline
\end{tabular}

Table 3: Density of UPR for the different initial curing temperatures.

\begin{tabular}{lrr}
\hline Number & Initial curing temperature $\left({ }^{\circ} \mathrm{C}\right)$ & Density $\left(\mathbf{g} / \mathbf{c m}^{3}\right)$ \\
\hline 1 & 10.9 & 1.218 \\
2 & 27.5 & 1.22 \\
3 & 35.2 & 1.22 \\
4 & 45.5 & 1.22 \\
\hline
\end{tabular}

both the liquid and solid stages but the density changed, which means the volume was smaller in the solid stage. Interestingly, for all initial curing temperatures, the density of UPR was almost the same. Thus, the volume shrinkage of polyester does not depend on the initial curing temperature.

\subsubsection{Thermo-gravimetric evaluation of unsaturated polyester resin}

There are some valuable information that can be provided by TGA measurements, such as the filler content of materials, composition of multi-component materials, decomposition kinetics, moisture and volatile content. Table 4 shows the behavior of UPR under elevated temperatures. It is clear that the degradation procedure was similar for the different samples. The degradation started at about $287^{\circ} \mathrm{C}$ with $\sim 5.7 \%$ mass loss and most of the UPR was gone at around $541.2^{\circ} \mathrm{C}(\sim 1.1 \%$ mass remained $)$. The small amount of mass reduction before degradation may be due to water absorption and/or volatile contents, while

Table 4: Thermal behavior of UPR for the different initial curing temperatures.

\begin{tabular}{|c|c|c|c|c|c|}
\hline \multirow[t]{2}{*}{ No. } & \multirow{2}{*}{$\begin{array}{r}\text { Initial curing } \\
\text { temperature } \\
\left({ }^{\circ} \mathrm{C}\right)\end{array}$} & \multicolumn{2}{|c|}{ Onset of degradation } & \multicolumn{2}{|c|}{ Residue } \\
\hline & & $\begin{array}{r}\text { Temperature } \\
\left({ }^{\circ} \mathrm{C}\right)\end{array}$ & $\begin{array}{r}\text { Mass } \\
(\%)\end{array}$ & $\begin{array}{r}\text { Temperature } \\
\left({ }^{\circ} \mathrm{C}\right)\end{array}$ & $\begin{array}{r}\text { Mass } \\
(\%)\end{array}$ \\
\hline 1 & 10.9 & 288.9 & 93.6 & 542.1 & 1.2 \\
\hline 2 & 27.5 & 286.8 & 94.2 & 541.1 & 1.3 \\
\hline 3 & 35.2 & 288.7 & 94.9 & 542.0 & 1.2 \\
\hline 4 & 45.5 & 283.4 & 94.5 & 539.6 & 0.7 \\
\hline
\end{tabular}

the mass retention after degradation (up to $800^{\circ} \mathrm{C}$ ) is possibly due to the impurities of UPR.

\subsubsection{Tensile properties of composite structures}

From Section 3.1.1 to Section 3.1.3, we have concluded that the optimum curing temperature should be started approximately in the range of $25-35^{\circ} \mathrm{C}$. In addition, Belloul et al. (53) showed the different optimum temperatures of resin $\left(30^{\circ} \mathrm{C}\right)$ and composite $\left(40^{\circ} \mathrm{C}\right)$ based on their tensile properties. Practically, the initial curing temperatures were indicated by the probe of the thermocouple at the center of samples in the previous section that may be a little bit different from the surrounding temperatures. Therefore, composite structures were fabricated to verify the effect of initial curing temperature range on the tensile properties. A CSM/woven/CSM/woven sample was fabricated as the stacking sequence of the composite structure by hand lay-up. The initial curing temperatures were $22^{\circ} \mathrm{C}$ (MC1), $30^{\circ} \mathrm{C}(\mathrm{MC} 2)$ and $32^{\circ} \mathrm{C}(\mathrm{MC} 3)$. The tensile properties of materials are shown in Figure 2. It is clear that tensile properties of composite materials are also sensitive to environmental temperature. Higher tensile strength (20.88\%) and elastic modulus $(18.16 \%)$ were obtained when initial curing temperature rose from $22^{\circ} \mathrm{C}$ to $32^{\circ} \mathrm{C}$.

\subsection{Effect of fibers}

\subsubsection{Thermo-gravimetric of composite structures}

Glass fibers are the main reinforcement components for composite materials in this study. The CSM has random

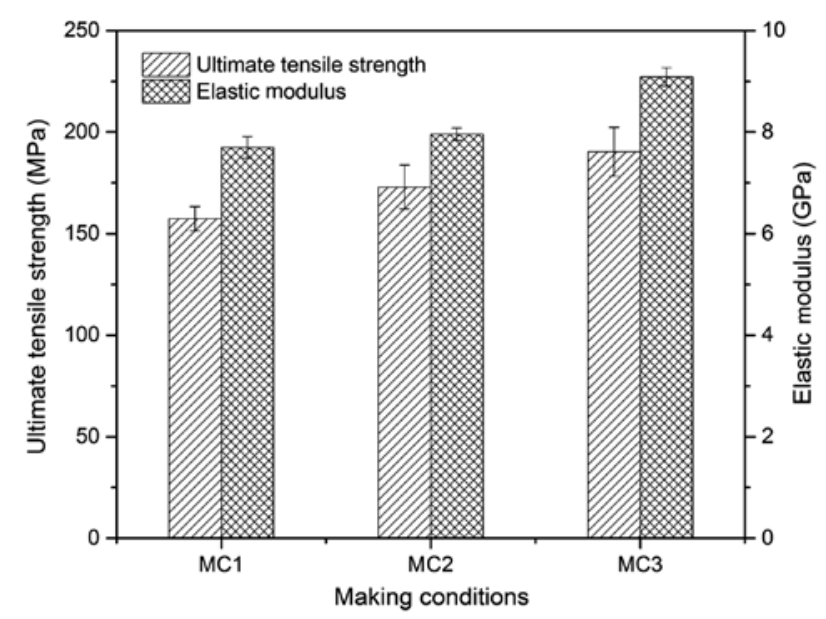

Figure 2: Tensile properties of CSM/woven/UPR for the different making conditions. 
directions and shorter lengths of fibers, while woven has orthogonal structures and longer fiber lengths. Therefore, the thermal gravimetric analysis was carried out to examine the thermal resistance with the appearance of different fibers. Figure 3 (solid lines) indicates a higher thermal resistance of composite materials due to the addition of glass fibers. Similarly, Budai et al. (56) also reported that the decomposition of UPR is delayed by adding glass fibers. Besides, the degradation rates of the materials are described by the dashed lines. The woven structure was the toughest candidate in this fiber group, as demonstrated by its highest onset degradation temperature and the lowest rate of decomposition. That means the longer fiber and specific fiber structures in woven really affect on the thermal resistance of composite materials. In addition, the residual masses remaining at high temperatures (from 500 to $800^{\circ} \mathrm{C}$ ) were different in each case. For example, at $700^{\circ} \mathrm{C}$, the mass retentions of UPR, UPR/CSM, UPR/woven, and UPR/combination of fibers were about $1.27 \%, 23.42 \%, 46.51 \%$ and $33.83 \%$, respectively. The parallel nature of both the solid and dashed lines in the high temperature range $\left(500-800^{\circ} \mathrm{C}\right)$ also indicates good thermal stability of the fibers. The mass retention represents the exact fiber content of composite structures. In comparison to the input values in Table 1, the mass of the fibers was conserved, except for the small amounts of moisture and volatiles. It can be concluded that the chemical compositions of CSM and woven are almost similar and the thermal degradation is slightly dependent on the fiber structure and significantly dependent on the fiber concentration in composite materials.

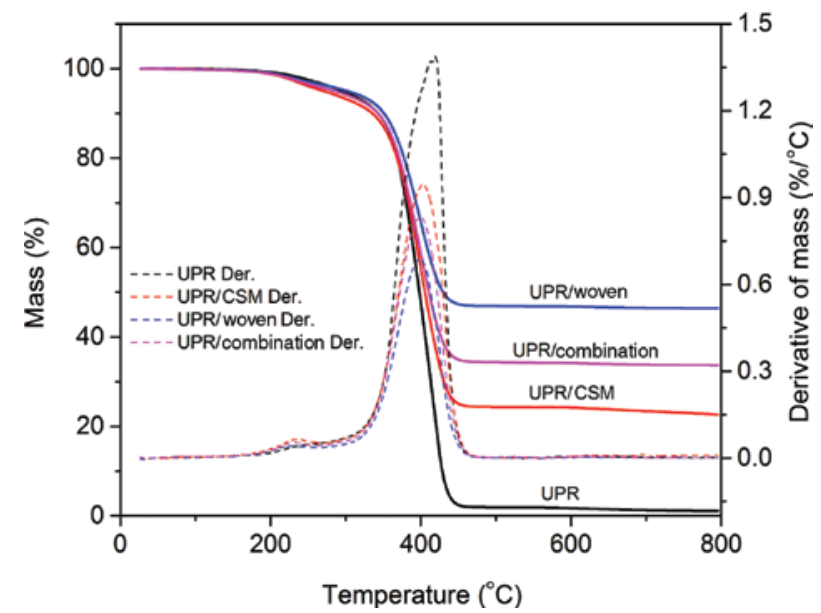

Figure 3: Effect of fibers on the thermo-gravimetric behavior of the composite structures.

\subsubsection{Tensile properties of composite structures}

According to the rule of mixtures (3), the mechanical properties of a fiber composite can be calculated based on volume fractions. Thus, the 2 times higher weight fraction of woven than CSM (Table 1) that can be estimated that mechanical properties of woven composite relatively are 2 times higher than CSM composite. In fact, the ultimate tensile strength and elastic modulus of CSM/UPR were $87.92 \mathrm{MPa}$ and $7.09 \mathrm{GPa}$, respectively (Figure 4). Meanwhile, the tensile strength of woven/ UPR was almost 2.8 times higher than that of the CSM composite, but Young's modulus of the woven composite was only $17.84 \%$ higher than that of CSM/UPR. Even though both fibers have almost similar chemical compositions (Section 3.2.1), woven composite has much higher mechanical properties than CSM that can be concluded about the higher fiber length (57) and orthotropic fiber arrangement of woven.

Practically, woven has higher surface density than CSM (Table 2), but there are some gaps on the surface of layer and fibers are bundled together (Figure 5). In comparison, woven may absorb less resin than CSM. In composite structures, CSM should be fabricated with a greater amount of UPR to ensure that the resin is fully filled into the fibers. As a consequence, woven fiber fraction is always higher than CSM that can result in a heavier product. In addition, woven has the native waviness surface that can be formed a rough surface composite structures. A composite laminate was fabricated by combining both of them as a CSM/woven/CSM/ woven structure to obtain the best function of fibers. As a result, the combination of fibers can obtain acceptable tensile properties at Figure 4. The CSM/woven/CSM/

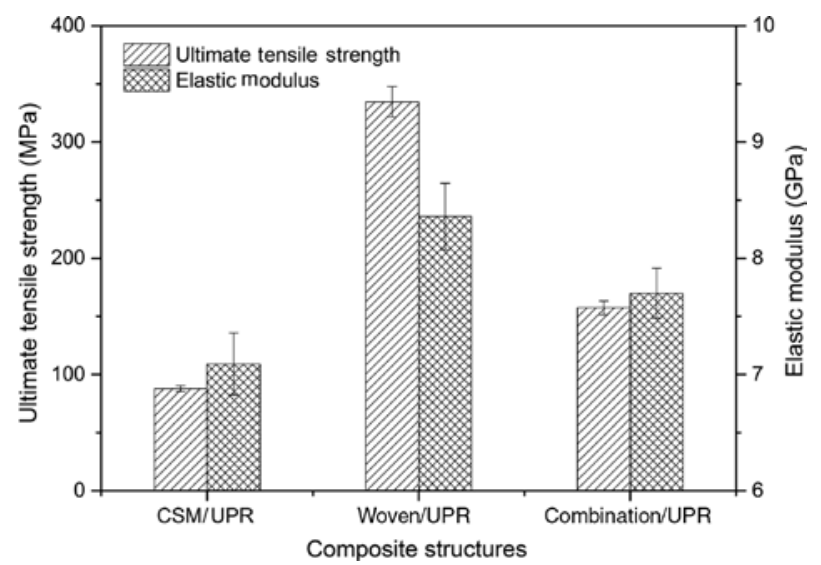

Figure 4: Tensile properties of composite structures with different of fiber components. 

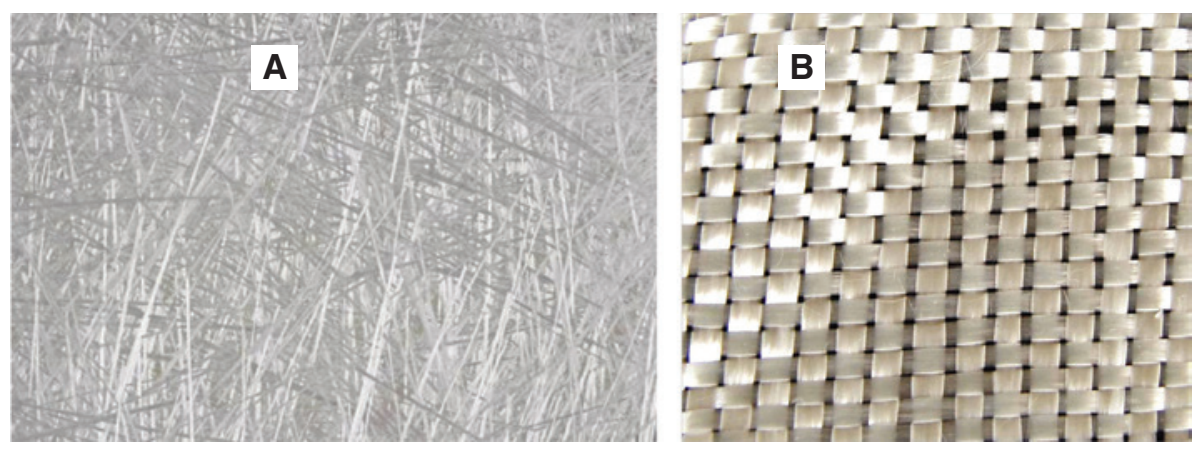

Figure 5: The different glass fiber types.

(A) CSM and (B) woven.

woven composite had a $79.02 \%$ higher ultimate tensile strength and a $8.54 \%$ higher elastic modulus than the CSM composite.

\subsection{Effect of a vacuum}

\subsubsection{Density of composite structures}

The vacuum was used after hand lay-up fabrication, which was know as the hybrid fabrication method (58). Specific structures were fabricated by this method to achieve higher density (lower void content) and mechanical properties. A vacuum is useful in isolating samples with the surrounding environment and removing the unnecessary resin from samples to bleeder, peel ply and even to the hose. In comparison to the compression molding method, a vacuum may have less of an effect on the mechanical properties but it is a simple, more flexible and convenient method with a variety of product geometries. In fact, the effect of a vacuum is strongly dependent on the polymerization process. A vacuum may not have much influence if it is applied after the transition formation period because the polymer cannot be transferred at much higher viscosity. Fortunately, the density of composite structures increased due to the longer curing time employed based on the optimum fabrication conditions. As can be observed in Figure 6, the density increased by 7.09\%, $10.51 \%$ and $11.63 \%$ in CSM/UPR, woven/UPR and combination/UPR, respectively. The density of CSM and woven were 2.494 and $2.546 \mathrm{~g} / \mathrm{cm}^{3}$ in the experiment. They are much higher than the density of composite structures and UPR. Therefore, the reason for increasing density in Figure 6 may be attributed to the removing of a significant amount of UPR.

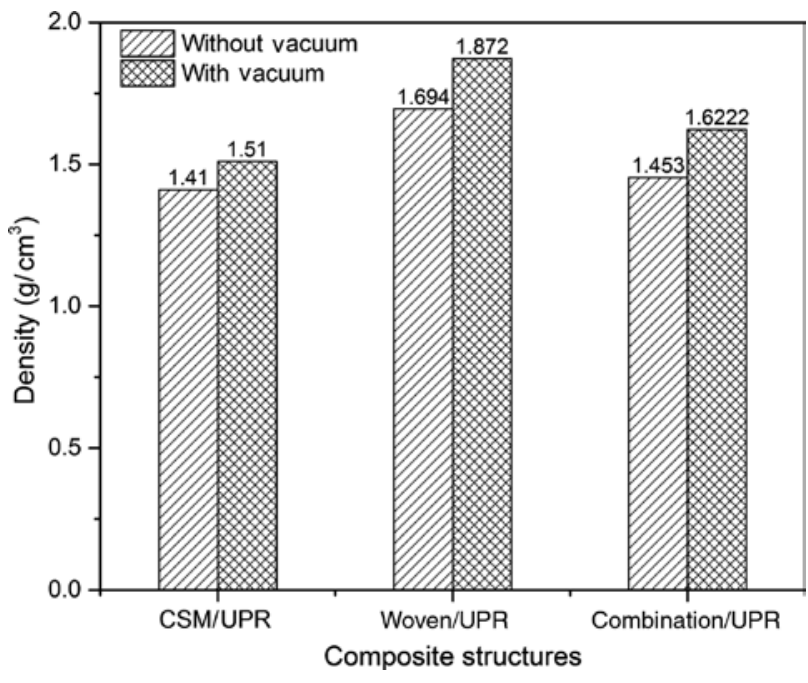

Figure 6: Effect of a vacuum on the density of composite structures.

\subsubsection{Thermo-gravimetric behavior of the composite structures}

The contents of the fibers in the composite structures with and without a vacuum are presented in Figure 7. It confirms that a vacuum has influenced on removing UPR in the composite structure from the TGA results. For instance, around the onset of degradation, a vacuum can reduce the mass loss by $1.41 \%, 2.18 \%$ and $2.49 \%$ for CSM, woven and fiber combination, respectively. Especially, more than twice the CMS and fiber combination contents were obtained, while $60.09 \%$ woven fiber was obtained with heating up to $800^{\circ} \mathrm{C}$.

It also can be seen that the mass loss rates are lower under a vacuum following the slope of curves at Figure 7 that means the better thermal stability of composite structures. If the mass retention represents the input fiber weight fraction, then it is recommended that less of UPR can be used for composites fabrication under the 


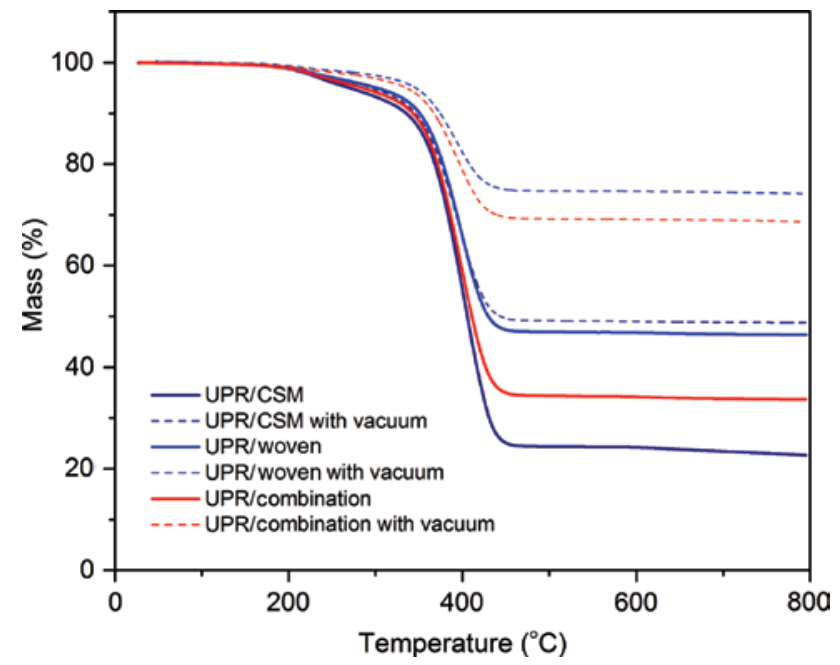

Figure 7: Effect of a vacuum on the thermo-gravimetric behavior of the composite structures.

certain vacuum conditions. The almost linear increment of mass retention from CSM, woven and their combination can emphasize that thermal resistance and decomposition of composite structure are mainly dependent on the utilized fiber ratios. The little higher UPR removing in CSM composite displayed the better effect from the vacuum pressure because woven is stiffer under the bundled form and UPR may be confined between woven gaps.

\subsubsection{Tensile properties of composite structures}

When a vacuum is applied, the vacuum flow can pullout the extra UPR and the vacuum pressure can generate compression condition. As a consequence, the crosssectional area of composite structures can be decreased. Therefore, the tensile properties of the composite structures could be increased proportionally in the elastic region $(58,59)$. Generally, the ultimate tensile strength and elastic modulus of composite structures were positively influenced by a vacuum (Figure $8 \mathrm{~A}$ and B). Indeed, the tensile strengths of CSM/UPR, woven/UPR and combination/UPR increased from 87.92 to $125.36 \mathrm{MPa}$, from 351.67 to $402.96 \mathrm{MPa}$ and from 190.26 to $258.14 \mathrm{MPa}$, respectively. Furthermore, the elastic modulus also increased by $38.63 \%$ in CSM/UPR, $24.31 \%$ in woven/ UPR and $42.46 \%$ in combination/UPR. These results can be also attributed to the continuous vacuum pressure which can remove most of the flaws and voids of the samples.
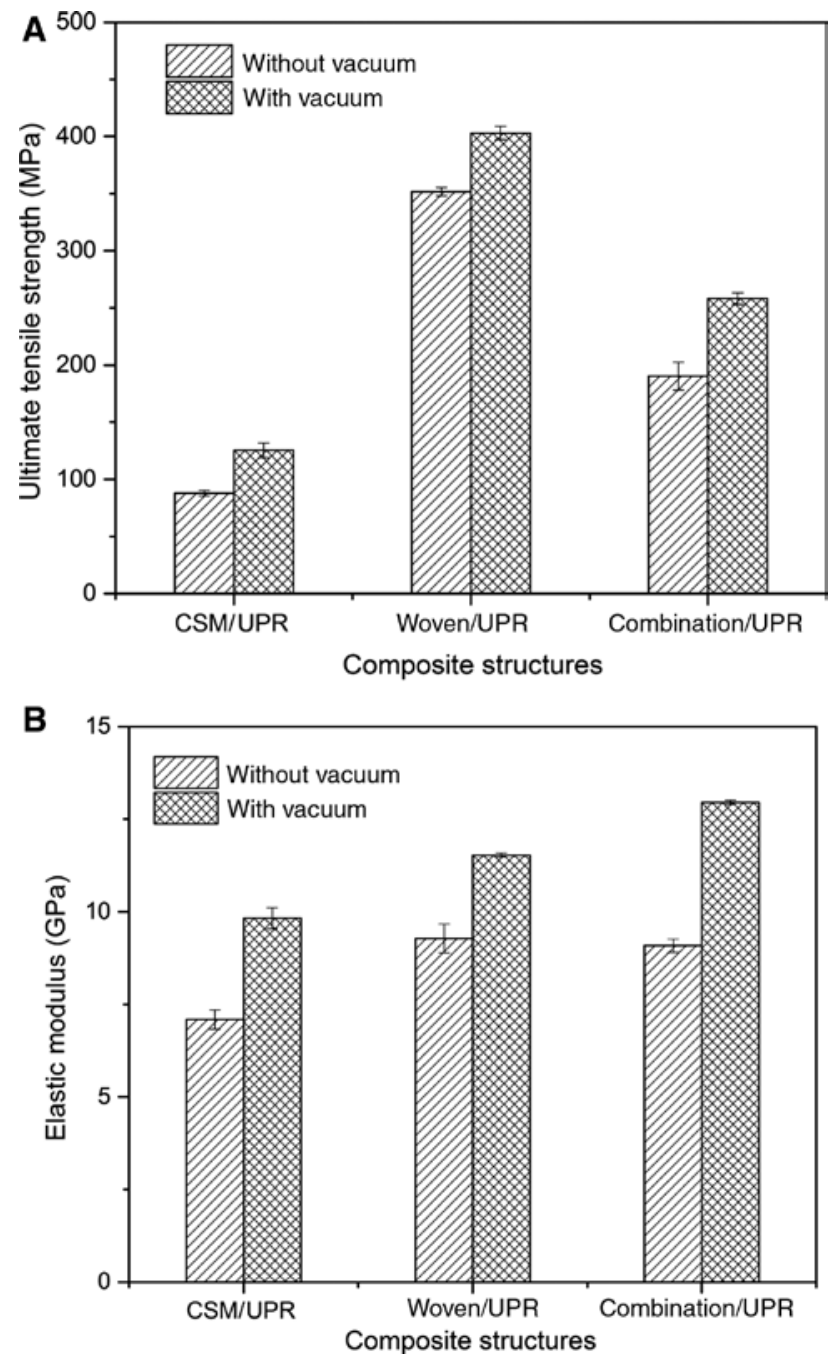

Figure 8: Effect of vacuum on the tensile properties of composite structures.

(A) Tensile strength and (B) elastic modulus.

\subsection{Effect of MWCNTs on the tensile properties of composite structures}

Based on the optimized conditions such as initial curing temperature, fiber changes and vacuum, the tensile properties of the various fibers composite structures were continuously investigated by adding $0.1 \mathrm{wt} . \%$ MWCNTs. The good effects of MWCNTs are clear due to the good tensile properties of all fibers composite structures were obtained (Figure 9). The tensile strength of CSM/UPR increased from 71.31 to $77.72 \mathrm{MPa}$ and Young's modulus increased from 6.70 to $7.34 \mathrm{GPa}$. Similarly, the tensile strength and elastic modulus of woven/UPR increased by $9.48 \%$ and $14.63 \%$, respectively. Finally, the strength and modulus of combination/UPR were enhanced by $25.29 \mathrm{MPa}(14.63 \%)$ and $1.39 \mathrm{GPa}(17.46 \%)$, 

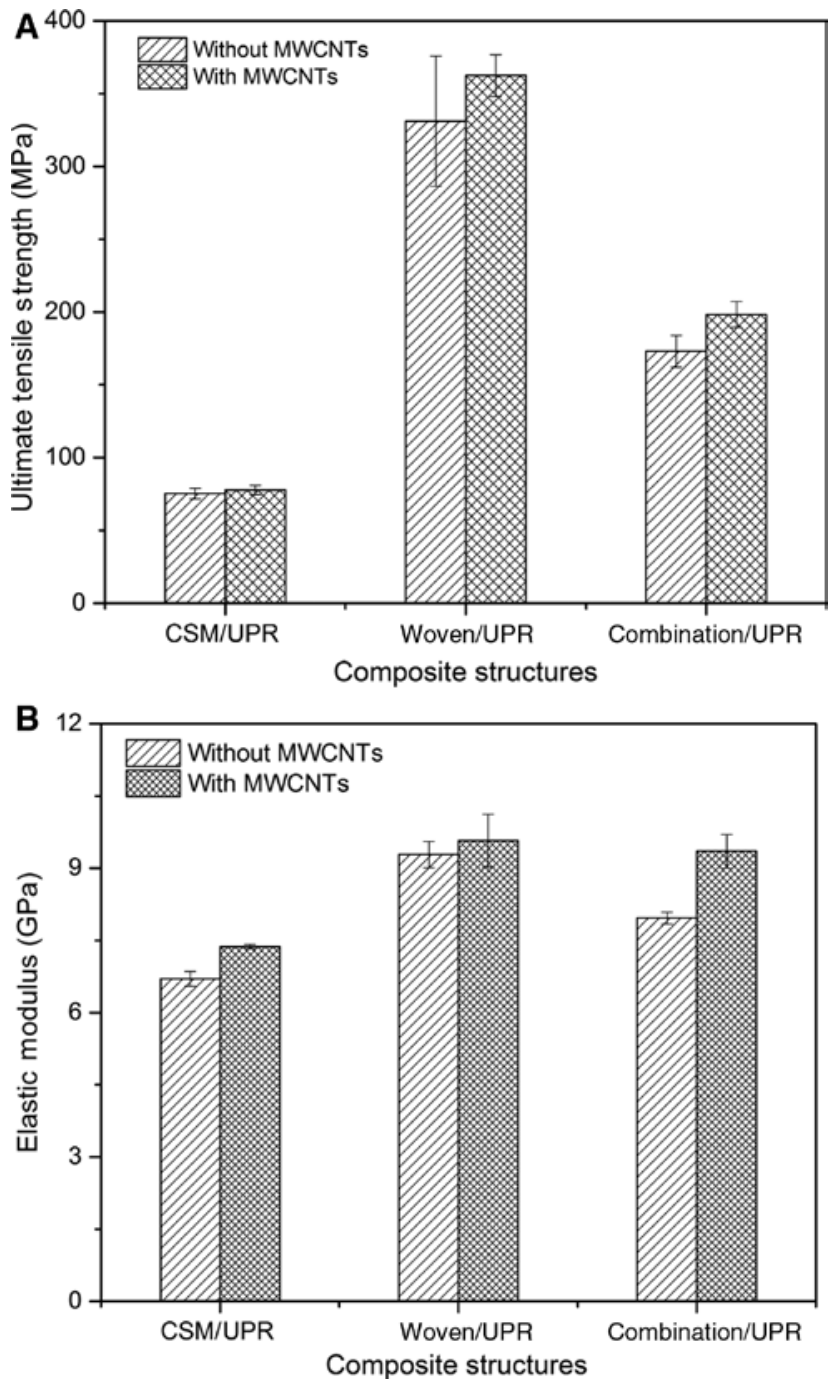

Figure 9: Effect of MWCNTs on the tensile properties of composite structures.

(A) Tensile strength and (B) elastic modulus.

respectively. In comparison, combination/UPR exhibits a little bit higher tensile properties after adding MWCNTs than woven composite, while CSM reproduces the lowest impact. Indeed, the raise of tensile properties in fibers composite expresses the important role of the appearance of MWCNTs. Previously, the adding $0.1 \mathrm{wt} . \%$ into UPR represented the good dispersion quality than other ratios of MWCNTs without any agglomerations of MWCNTs in field emission-scanning electron microscope (FE-SEM) results, that means there was no stress concentration in modified UPR. Consequently, the tensile stress transferred well from UPR to MWCNTs, then the higher of $42.14 \%$ tensile strength and $14.33 \%$ elastic modulus were achieved in our previous work (50). Compared to the improvement of tensile properties and the weight fraction of all components of various fibers/modified UPR composite in the current results, we can see that the performance of $0.1 \mathrm{wt} . \%$ MWCNTs is almost conserved.

As we observed, composite structures, especially polyester, are very sensitive to the environment. In addition, the composite fabrication procedure is complicated involving many steps such as stacking several fiber layers, especially applying bleeder, peel ply and a vacuum bag before employing a vacuum pump. That may take more time while curing already occurred in a previous step. Therefore, choosing the appropriate moment and initial temperature for fabrication was the biggest difficulty in the experiments to get a better effect of using a vacuum before the UPR is cured. In comparison, the results in the Section 3.3.2 discussed that the tensile properties of the nanocomposite structures were lower. The main reason may be attributed to the difference of the initial curing temperature and the time of applying vacuum.

\section{Conclusions}

In this study, the optimum conditions for modifying UPR by MWCNTs were determined considering the exothermic temperature and curing time. The behavior of conventional glass fiber/UPR composites was evaluated based on their density, thermal resistance and tensile properties. The fiber changes strongly impacted the density and tensile properties of the composite structures. The applied vacuum had a good effect on all of the factors (density, decomposition and tensile properties). Finally, MWCNTs also possessed a positive influence on the tensile properties of the composite structure under the optimum conditions such as initial curing temperature in our current investigation and some other conditions from our previous work (50) such as mixing temperature, hardener ratio and weight percent of MWCNTs. Additionally, mixing conditions of the simple modification object (UPR) and dispersion method (stir method) are close to the realistic processes used in the industry. They not only indicate the enhanced mechanical properties of composite materials, but also realize the safe working conditions (less harmful, lower exothermic temperature and shorter time in fabrication). Therefore, the results in this study could be widely applied for mass production.

Acknowledgment: This work was supported by the 2016 Research Fund of the University of Ulsan. 


\section{References}

1. Sathishkumar TP, Satheeshkumar S, Naveen J. Glass fiberreinforced polymer composites-a review. J Reinf Plast Compos. 2014;33:1258-75.

2. Scheirs J, Long TE, editors. Modern polyesters: chemistry and technology of polyesters and copolyesters. Hoboken, NJ: John Wiley \& Sons; 2005. 699 p.

3. Jones RM. Mechanics of composite materials. 2nd ed. Boca Raton, FL: CRC press; 1998. 26 p.

4. Shan Z, Qin S, Liu Q, Liu F. Key manufacturing technology \& equipment for energy saving and emissions reduction in mechanical equipment industry. Int J Precis Eng Manuf. 2012;13:1095-100.

5. Song X. Vacuum assisted resin transfer molding (VARTM): model development and verification. Blacksburg, VA: Doctoral dissertation, Virginia Polytechnic Institute and State University; 2003.

6. Erden S, Sever K, Seki Y, Sarikanat M. Enhancement of the mechanical properties of glass/polyester composites via matrix modification glass/polyester composite siloxane matrix modification. Fiber Polym. 2010;11:732-7.

7. lijima S. Helical microtubules of graphitic carbon. Nature 1991;354:56-8.

8. Allaoui A, Bai S, Cheng HM, Bai JB. Mechanical and electrical properties of a MWNT/epoxy composite. Compos Sci Technol. 2002;62:1993-8.

9. Montazeri A, Javadpour J, Khavandi A, Tcharkhtchi A, Mohajeri A. Mechanical properties of multi-walled carbon nanotube/epoxy composites. Mater Des. 2010;31:4202-8.

10. Guo P, Chen X, Gao X, Song H, Shen H. Fabrication and mechanical properties of well-dispersed multiwalled carbon nanotubes/ epoxy composites. Compos Sci Technol. 2007;67:3331-7.

11. Coleman JN, Khan U, Blau WJ, Gun'ko YK. Small but strong: a review of the mechanical properties of carbon nanotube-polymer composites. Carbon 2006;44:1624-52.

12. Yeh MK, Tai NH, Liu JH. Mechanical behavior of phenolic-based composites reinforced with multi-walled carbon nanotubes. Carbon 2006;44:1-9.

13. Shokrieh MM, Saeedi A, Chitsazzadeh M. Mechanical properties of multi-walled carbon nanotube/polyester nanocomposites. J Nanostruct Chem. 2013;3:1-5.

14. Ma PC, Siddiqui NA, Marom G, Kim JK. Dispersion and functionalization of carbon nanotubes for polymer-based nanocomposites: a review. Compos Part A Appl Sci Manuf. 2010;41:1345-67.

15. Seyhan AT, Gojny FH, Tanoğlu M, Schulte K. Critical aspects related to processing of carbon nanotube/unsaturated thermoset polyester nanocomposites. Eur Polym J. 2007;43:374-9.

16. Li WZ, Wang DZ, Yang SX, Wen JG, Ren ZF. Controlled growth of carbon nanotubes on graphite foil by chemical vapor deposition. Chem Phys Lett. 2001;335:141-9.

17. Zhu S, Su CH, Lehoczky SL, Muntele I, Ila D. Carbon nanotube growth on carbon fibers. Diam Relat Mater. 2003;12:1825-8.

18. De Riccardis MF, Carbone D, Makris TD, Giorgi R, Lisi N, Salernitano $E$. Anchorage of carbon nanotubes grown on carbon fibres. Carbon 2006;44:671-4.

19. Laachachi A, Vivet A, Nouet G, Doudou BB, Poilane C, Chen J, Ayachi $\mathrm{MH}$. A chemical method to graft carbon nanotubes onto a carbon fiber. Mater Lett. 2008;62:394-7.
20. Gong QJ, Li HJ, Wang X, Fu QG, Wang ZW, Li KZ. In situ catalytic growth of carbon nanotubes on the surface of carbon cloth. Compos Sci Technol. 2007;67:2986-9.

21. Zhao J, Liu L, Guo Q, Shi J, Zhai G, Song J, Liu Z. Growth of carbon nanotubes on the surface of carbon fibers. Carbon 2008;46:380-3.

22. De Greef N, Zhang L, Magrez A, Forró L, Locquet JP, Verpoest I, Seo JW. Direct growth of carbon nanotubes on carbon fibers: Effect of the CVD parameters on the degradation of mechanical properties of carbon fibers. Diam Relat Mater. 2015;51:39-48.

23. Thostenson ET, Li WZ, Wang DZ, Ren ZF, Chou TW. Carbon nanotube/carbon fiber hybrid multiscale composites. J Appl Phys. 2002;91:6034-7.

24. Mathur RB, Chatterjee S, Singh BP. Growth of carbon nanotubes on carbon fibre substrates to produce hybrid/phenolic composites with improved mechanical properties. Compos Sci Technol. 2008;68:1608-15.

25. Kepple KL, Sanborn GP, Lacasse PA, Gruenberg KM, Ready WJ. Improved fracture toughness of carbon fiber composite functionalized with multi walled carbon nanotubes. Carbon 2008;46:2026-33.

26. Sager RJ, Klein PJ, Lagoudas DC, Zhang Q, Liu J, Dai L, Baur JW. Effect of carbon nanotubes on the interfacial shear strength of T650 carbon fiber in an epoxy matrix. Compos Sci Technol. 2009;69:898-904.

27. Kar KK, Rahaman A, Agnihotri P, Sathiyamoorthy D. Synthesis of carbon nanotubes on the surface of carbon fiber/fabric by catalytic chemical vapor deposition and their characterization. Fuller Nanotub Car Nanostruct. 2009;17:209-29.

28. Dai J, Soliman E, Safdari M, Al-Haik M, Reda Taha MM. Effect of carbon nanotube growth conditions on strength and stiffness of carbon and glass fiber polymer composites. In Proceedings of 51st AIAA/ASME/ASCE/AHS/ASC Structures. Structural Dynamics, and Materials Conference, Orlando, Florida, USA; 2010.

29. Sharma SP, Lakkad SC. Effect of CNTs growth on carbon fibers on the tensile strength of CNTs grown carbon fiber-reinforced polymer matrix composites. Compos Part A Appl Sci Manuf. 2011;42:8-15.

30. An F, Lu C, Li Y, Guo J, Lu X, Lu H, He S, Yang Y. Preparation and characterization of carbon nanotube-hybridized carbon fiber to reinforce epoxy composite. Mater Des. 2012;33:197-202.

31. Zu M, Li Q, Zhu Y, Dey M, Wang G, Lu W, Deitzel JM, Gillespie JW, Byun JH, Chou TW. The effective interfacial shear strength of carbon nanotube fibers in an epoxy matrix characterized by a microdroplet test. Carbon 2012;50:1271-9.

32. Jamnani BD, Hosseini S, Rahmanian S, Rashid SA, Balavandy SK. Grafting carbon nanotubes on glass fiber by dip coating technique to enhance tensile and interfacial shear strength. J Nanomater. 2015;16:1-7.

33. Lili S, Yan Z, Yuexin D, Zuoguang Z. Interlaminar shear property of modified glass fiber-reinforced polymer with different MWCNTs. Chin J Aeronaut. 2008;21:361-9.

34. Godara A, Mezzo L, Luizi F, Warrier A, Lomov SV, Van Vuure AW, Gorbatikh L, Moldenaers P, Verpoest I. Influence of carbon nanotube reinforcement on the processing and the mechanical behaviour of carbon fiber/epoxy composites. Carbon 2009;47:2914-23.

35. Rahman MM, Zainuddin S, Hosur MV, Malone JE, Salam MB, Kumar A, Jeelani S. Improvements in mechanical and thermo-mechanical properties of e-glass/epoxy composites using amino functionalized MWCNTs. Compos Struct. 2012;94:2397-406. 
36. Rahman MM, Zainuddin S, Hosur MV, Robertson CJ, Kumar A, Trovillion J, Jeelani S. Effect of NH 2-MWCNTs on crosslink density of epoxy matrix and ILSS properties of e-glass/epoxy composites. Compos Struct. 2013;95:213-21.

37. Shokrieh MM, Saeedi A, Chitsazzadeh M. Evaluating the effects of multi-walled carbon nanotubes on the mechanical properties of chopped strand mat/polyester composites. Mater Des. 2014;56:274-9.

38. Taraghi I, Fereidoon A, Mohyeddin A. The effect of MWCNTs on the mechanical properties of Woven Kevlar/epoxy composites. Steel Compos Struct. 2014;17:825-34.

39. Genedy M, Daghash S, Soliman E, Taha MM. Improving fatigue performance of GFRP composite using carbon nanotubes. Fibers 2015;3:13-29.

40. Tarfaoui M, Lafdi K, El Moumen A. Mechanical properties of carbon nanotubes based polymer composites. Compos Part B Eng. 2016;103:113-21.

41. Mahato KK, Rathore DK, Prusty RK, Dutta K, Ray BC. Tensile behavior of MWCNT enhanced glass fiber reinforced polymeric composites at various crosshead speeds. In IOP Conference Series: Mater Sci Eng. 2017;178:1-7.

42. Warrier A, Godara A, Rochez O, Mezzo L, Luizi F, Gorbatikh L, Lomov SV, VanVuure AW, Verpoest I. The effect of adding carbon nanotubes to glass/epoxy composites in the fibre sizing and/or the matrix. Compos Part A: Appl Sci Manuf. 2010;41:532-8.

43. Godara A, Gorbatikh L, Kalinka G, Warrier A, Rochez O, Mezzo L, Luizi F, Van Vuure AW, Lomov SV, Verpoest I. Interfacial shear strength of a glass fiber/epoxy bonding in composites modified with carbon nanotubes. Compos Sci Technol. 2010;70:1346-52.

44. Qian D, Dickey EC, Andrews R, Rantell T. Load transfer and deformation mechanisms in carbon nanotube-polystyrene composites. Appl Phys Lett. 2000;76:2868-70.

45. Haque A, Ramasetty A. Theoretical study of stress transfer in carbon nanotube reinforced polymer matrix composites. Compos Struct. 2005;71:68-77.

46. Behabtu N, Green MJ, Pasquali M. Carbon nanotube-based neat fibers. Nano Today. 2008;3:24-34.

47. Wu AS, Chou TW. Carbon nanotube fibers for advanced composites. Mater Today. 2012;15:302-10.
48. Veedu VP, Cao A, Li X, Ma K, Soldano C, Kar S, Ajayan PM, Ghasemi-Nejhad MN. Multifunctional composites using reinforced laminae with carbon-nanotube forests. Nat Mater. 2006;5:457-62.

49. Bhanushali H, Bradford PD. Woven glass fiber composites with aligned carbon nanotube sheet interlayers. J Nanomater. 2016;2016:1-9.

50. Hoang VT, Yum YJ. Optimization of mixing process and effect of multi-walled carbon nanotubes on tensile properties of unsaturated polyester resin in composite materials. J Mech Sci Technol. 2017;31:1621-7.

51. Huang YJ, Leu JS. Curing of unsaturated polyester resins. Effects of temperature and initiator: 1 . Low temperature reactions. Polymer 1993;34:295-304.

52. Toorkey RF, Rajanna KC, Prakash PS. Curing of unsaturated polyester: network formation. J Chem Educ. 1996;73:372-3.

53. Belloul N, Ahmed-Benyahia A, Serier A, Ouali N. Effect of temperature and initiator on glass fibre/unsaturated polyester composite: cross-linking, mechanical properties. In: Boukharouba T, Elboujdaini M, Pluvinage G, editors. Damage and fracture mechanics. Dordrecht: Springer; 2009. 497 p.

54. Zhang J, Xu YC, Huang P. Effect of cure cycle on curing process and hardness for epoxy resin. Express Polym Lett. 2009;3:534-41.

55. Kelly A, Zweben C, editors. Comprehensive composite materials. Kidlington, Oxford: Elsevier Science Ltd.; 2000. Volume 2. 1-57 pp.

56. Budai Z, Sulyok Z, Vargha V. Glass-fibre reinforced composite materials based on unsaturated polyester resins. J Therm Anal Calorim. 2012;109:1533-44.

57. Miwa M, Ohsawa T, Tahara K. Effects of fiber length on the tensile strength of epoxy/glass fiber and polyester/glass fiber composites. J Appl Polym Sci. 1980;25(5):795-807.

58. Kim DW, Hennigan DJ, Beavers KD. Effect of fabrication processes on mechanical properties of glass fiber reinforced polymer composites for 49 meter (160 foot) recreational yachts. Inter J Naval Architect Ocean Eng. 2010;2(1):45-56.

59. Kim SY, Shim CS, Sturtevant C, Kim DW, Song HC. Mechanical properties and production quality of hand-layup and vacuum infusion processed hybrid composite materials for GFRP marine structures. Inter I Naval Architect Ocean Eng. 2014;6(3):723-36. 